\title{
Effect of alpha-glucosidase inhibitors on progression of carotid intima-media thickness and incidence of diabetes in patients with impaired glucose tolerance: A meta-analysis
}

\author{
Hnin Hnin Hlaing MBBS*, Ge Xu MD PhD*
}

\begin{abstract}
HH Hlaing, Ge Xu. Effect of alpha-glucosidase inhibitors on progression of carotid intima-media thickness and incidence of diabetes in patients with impaired glucose tolerance: A metaanalysis. Curr Res Cardiol 2014;1(2):102-106.
\end{abstract}

BACKGROUND: Impaired glucose tolerance (IGT) is associated with increased cardiovascular risk. Little is known whether alpha-glucosidase inhibitors (alpha-GIs) can prevent the progression of carotid intima-media thickness (IMT) or the incidence of diabetes, and whether they have any effect on inflammatory biomarkers such as C-reactive protein (CRP) in IGT patients.

OBJECTIVE: To perform a systematic review on the effect of acarbose on carotid IMT, incidence of diabetes and CRP in patients with IGT.

METHODS AND RESULTS: A meta-analysis of randomized controlled trials (RCTs) comparing acarbose with control group in prediabetes patients was conducted. Eleven RCTs with 2699 patients were included.

\begin{abstract}
Alpha-GI therapy was associated with a significant reduction in progression of carotid IMT (weighted mean difference $-0.12 \mathrm{~mm}[95 \% \mathrm{Cl}$ $-0.20 \mathrm{~mm}$ to $-0.04 \mathrm{~mm}$; $\mathrm{P}<0.004)$. It was also associated with decrease in progression of diabetes $(\mathrm{OR}=0.46[95 \% \mathrm{CI} 0.33$ to 0.65$]$; $\mathrm{P}<0.00001)$ and a significant reduction in serum CRP (weighted mean difference $-1.34 \mathrm{mg} / \mathrm{L}$ [95\% CI $-1.91 \mathrm{mg} / \mathrm{L}$ to $-0.77 \mathrm{mg} / \mathrm{L}] ; \mathrm{P}<0.00001)$.

CONCLUSION: The present study suggests that alpha-GI therapy in IGT patients inhibits the progression of diabetes and carotid IMT. The underlying mechanism for preventing carotid IMT progression may be through reducing inflammatory biomarkers such as CRP. More RCTs still need to be carried out to further understand the effect of alpha-GIs on atherosclerosis.
\end{abstract}

Key Words: Acarbose; Alpha-glucosidase inhibitor; Atherosclerosis; C-reactive protein; Carotid intima media thickness; Glucose intolerance; Impaired glucose tolerance; Inflammatory markers

\begin{abstract}
Increasing prevalence of type 2 diabetes mellitis (T2DM) and impaired glucose tolerance (IGT) is a major health concern in both developed and developing countries around the world. It is estimated that 439 million adults will have diabetes by 2030, and there will be a $69 \%$ increase in number of adults with diabetes in developing countries and 20\% increase in developed countries between 2010 and 2013 (1). The association between diabetes mellitus and cardiovascular diseases has been well established. Haffner et al (2) demonstrated that in patients with T2DM without a previous history of myocardial infarction (MI), the incidence of MI is equal to or greater than that of nondiabetic individuals with previous MI. On the other hand, IGT is considered to be the intermediate stage between normal glucose tolerance and overt diabetes mellitus. People with IGT not only have increased risk of developing T2DM, but also have increased risk of developing atherosclerosis and cardiovascular disease. Several studies have suggested that cardiovascular mortality in patients with IGT is close to that of individuals with T2DM $(3,4)$. The Funagata Diabetes Study (3) demonstrated that the cumulative survival rate from cardiovascular disease for IGT was significantly lower than that for normal glucose tolerance $(0.962$ versus $0.988 ; \mathrm{P}<0.05)$.

Carotid intima-media thickness (IMT) values and changes in IMT have been reported to be significantly associated with the risk of coronary artery disease and stroke (5). It has been increasingly used as a surrogate marker for atherosclerosis and predictor of future cardiovascular events. On the other hand, postprandial hyperglycemia plays an important role in endothelial dysfunction and subsequent cardiovascular complications. It has been shown that chronic subclinical inflammation indicated by elevated serum C-reactive protein (CRP) level is strongly associated with postchallenge glycemia (6).
\end{abstract}

The alpha-glucosidase inhibitor (alpha-GI) is an oral hypoglycemic drug that delays glucose release from complex carbohydrates and, thus, lowers the postprandial blood glucose levels (7). It has been reported that alpha-GIs prevent increases in carotid IMT in patients with diabetes and prediabetes. In a subgroup analysis of patients with IGT in the Study to Prevent Non-Insulin Dependent Diabetes Mellitus, the annual increase of IMT mean was reduced by approximately $50 \%$ in the acarbose group versus placebo. Koyasu et al (7) also showed that treatment with acarbose in patients with IGT or T2DM was associated with a beneficial effect in preventing the progression of carotid IMT compared with control $(\mathrm{P}<0.001)$. Research regarding whether alpha-GI therapy in patients with IGT can prevent the progression of atherosclerosis is inconclusive. The effect of alpha-GI therapy on carotid IMT progression in patients with IGT has yet to be examined. Similarly, it is not yet known whether therapy aiming at postprandial hyperglycemia would affect the serum CRP level or prevent atherosclerotic plaque progression. The present study aims to determine whether acarbose therapy has an effect on progression of carotid IMT in patients with IGT and whether the therapy is associated with serum CRP level.

Search strategy

\section{METHODS}

Electronic databases including PubMed (1966 to March 2012), the Cochrane Library (March 2012), Embase (1980 to 2011), and Chinese databases Wanfang and CNKI were searched. The MEsh and key words used were "glucose intolerance", "alpha-glucosidases", "acarbose", "voglibose" and "miglitol". For use with Chinese databases, the strategy was adapted slightly because these databases have different interfaces. Reference lists of identified studies were scrutinized to

*The authors contributed equally to this work

Department of Cardiovascular Medicine, Guangxi Medical University, The First Affiliated Hospital, Nanning, Guangxi, China

Correspondence: Dr Ge Xu, Department of Cardiovascular Medicine, Cardiovascular Research Institute, Guangxi Medical University, The First Affiliated

Hospital, 6 ShuangYong Road, Nanning, Guangxi 530021, China. Telephone 86-13471046321, e-mail 402172241@qq.com 


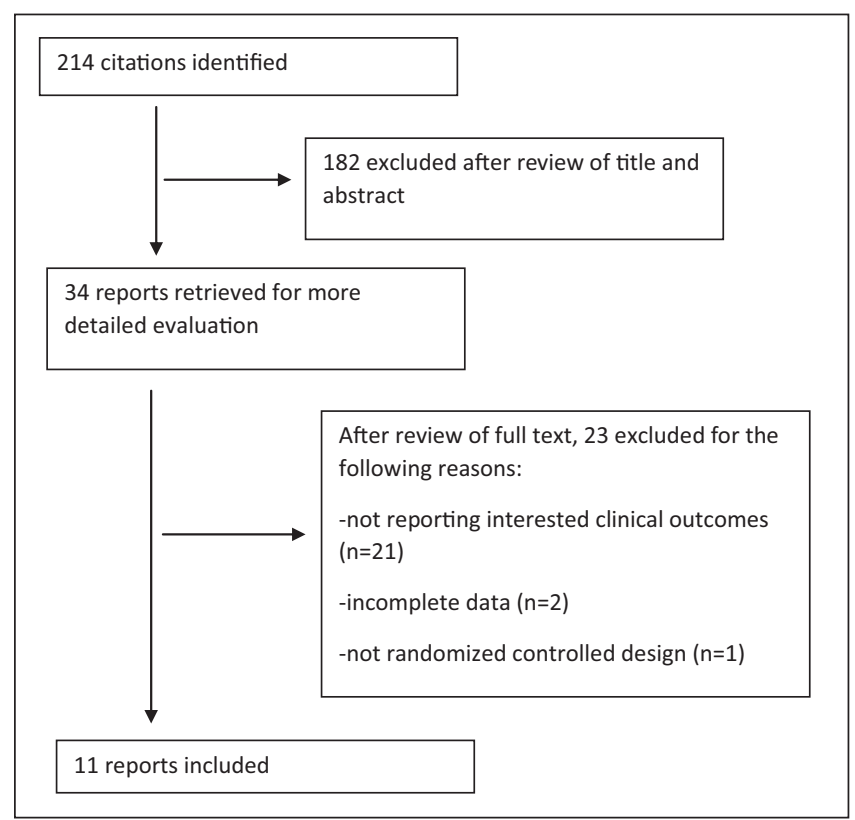

Figure 1) Overview of study selection

reveal additional sources. Conference proceedings from American College of Cardiology, American Heart Association and American Diabetes Association were also searched. There was no restriction on language and publication.

\section{Criteria for study selection}

Two reviewers independently checked the titles, abstract and keywords of every record retrieved. Full articles were retrieved for further assessment when the information given suggested that the study: included patients with IGT; compared alpha-GIs with placebo, no treatment or any other control; was a randomized controlled trial (RCT); and measured the carotid IMT, CRP or progression to diabetes as an outcome. In case of any doubt regarding these criteria from the information given by the title and abstract, the full article was retrieved for clarification. A third party was consulted in case of any differences in opinion between the two reviewers.

\section{Outcome measures}

The primary outcome measures were the change in carotid IMT, progression to diabetes at the end of follow-up and changes in CRP level. The secondary outcome measures were metabolic parameters including fasting plasma glucose (FBG), postprandial plasma glucose (PBG), glycosylated hemoglobin (HbA1c), total cholesterol, low-density lipoprotein, high-density lipoprotein (HDL), triglycerides, body mass index (BMI) and side effects.

\section{Data extraction}

Data on intervention and outcomes were extracted independently by two reviewers. Discrepancies were resolved by a third party. The data extracted included the following: demographics of the study participants (age, sex, race, BMI), interventions (type and dose of antidiabetic agents, other hypoglycemic measures), metabolic states (FBG, PBG, total cholesterol, low-density lipoprotein, HDL, triglycerides), carotid IMT, plasma CRP at baseline and follow-up. The quality of included studies was assessed according to several domains: randomization, generation of random sequence, allocation, blinding, completeness of follow-up and use of intention-to-treat analysis.

\section{Statistical analysis}

Review Manager 5.0 (The Cochrane Collaboration, England) software was used for the statistical analysis. Weighted mean difference

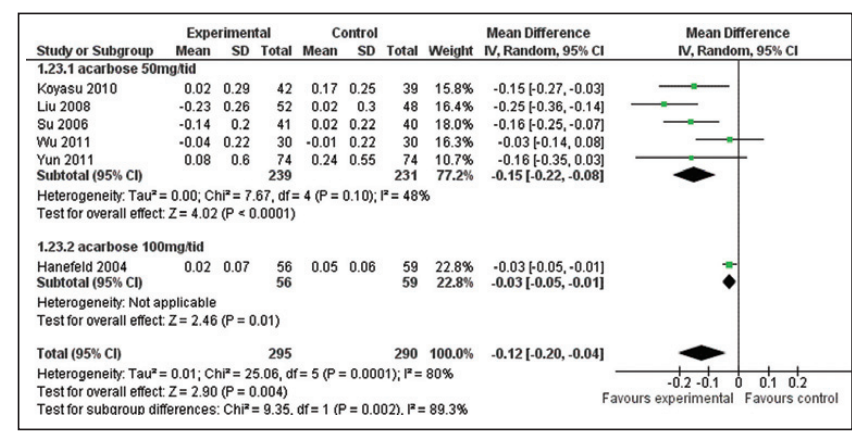

Figure 2) Alpha glucosidase inhibitor on the progression of carotid intima media thickness in patients with impaired glucose tolerance $(\mathrm{mm})$. IV Inverse variance

(WMD) and 95\% CIs were used for continuous outcomes. Heterogeneity across trials was assessed using a standard $\chi^{2}$ test with significance set at $\mathrm{P}<0.10$ and by means of $\mathrm{I}^{2}$ statistic with significance set at $\mathrm{I}^{2}>50 \%$. In view of significant clinical and methodological variability among the trials, a random effects model was chosen.

\section{RESULTS}

The search identified 214 citations. After a review of titles and abstracts, 34 full articles were read and 23 were judged to be ineligible for inclusion: 21 studies did not report the outcomes of interest, two did not have complete data and the authors could not be contacted, and one was not an RCT. In total, 11 RCTs with 2699 patients were included in the meta-analysis (Figure 1).

\section{Baseline characteristics}

The methodological and baseline characteristics of included trials are summarized in Table 1 . The confounding factors that affected the progression of carotid IMT, such as age, BMI, HbA1c and carotid IMT at baseline were well balanced in each arm. All trials enrolled patients with impaired glucose tolerance, $8.6 \%$ of patients were European ( 233 of 2699) and the rest were Asian. Acarbose was used in 10 trials and voglibose was used in one trial. In the majority of the trials, the dose of the acarbose used was $50 \mathrm{mg}$ three times a day; in one trial, $100 \mathrm{mg}$ three times a day was used and in another, $50 \mathrm{mg}$ twice a day was used. The dose of voglibose used was $0.2 \mathrm{mg}$ three times a day.

\section{Progression of carotid IMT at follow-up}

Alpha-GI therapy was associated with a reduction in progression of carotid IMT (WMD $-0.12 \mathrm{~mm}$ [95\% CI $-0.20 \mathrm{~mm}$ to $-0.04 \mathrm{~mm}$; $\mathrm{P}=0.0004$ ). In subgroup analysis, alpha-GI therapy at a dose of $100 \mathrm{mg}$ three times a day was associated with a reduction in progression of carotid IMT (WMD $-0.03 \mathrm{~mm}$ [95\% CI $-0.05 \mathrm{~mm}$ to $-0.01 \mathrm{~mm}$ ]; $\mathrm{P}=0.01$ ). Alpha-GI therapy at a dose of $50 \mathrm{mg}$ three times a day was associated with a reduction in progression of carotid IMT (WMD $-0.15 \mathrm{~mm}[95 \% \mathrm{CI}-0.22 \mathrm{~mm}$ to $-0.08 \mathrm{~mm}] ; \mathrm{P}<0.0001$ )(Figure 2).

\section{Changes in incidence of diabetes}

Alpha-GI reduced the incidence of (conversion to) T2DM in the treatment group (OR 0.46 [95\% CI 0.33 to 0.65]; $\mathrm{P}<0.00001$ ).

\section{Changes in CRP level}

Alpha-GI therapy was associated with a reduction in serum CRP level (WMD $-1.05 \mathrm{mg} / \mathrm{L}$ [95\% CI $-1.36 \mathrm{mg} / \mathrm{L}$ to $-0.73 \mathrm{mg} / \mathrm{L}]$; $\mathrm{P}<0.00001)$.

\section{Changes in metabolic parameters}

The difference in changes of metabolic parameters between the two groups is summarized in Table 2. Acarbose treatment was associated with significant decrease in $2 \mathrm{~h}$ postprandial glucose (WMD $-1.70 \mathrm{mmol} / \mathrm{L}$ 
TABLE 1

Baseline characteristics and study quality of included trials

\begin{tabular}{|c|c|c|c|c|c|c|c|c|c|c|c|}
\hline Characteristic & $\begin{array}{l}\text { Hanefeld } \\
\text { et al, } \\
2004 \text { (11) }\end{array}$ & $\begin{array}{c}\text { Huang } \\
\text { et al, } \\
2008(24)\end{array}$ & $\begin{array}{c}\text { Liu } \\
\text { et al, } \\
2008(23)\end{array}$ & $\begin{array}{c}\text { Yu } \\
\text { et al, } \\
2011(18)\end{array}$ & $\begin{array}{c}\text { Su } \\
\text { et al, } \\
2006(19)\end{array}$ & $\begin{array}{c}\text { Tang } \\
\text { et al, } \\
2008(20)\end{array}$ & $\begin{array}{c}\text { Wu } \\
\text { et al, } \\
2011(22)\end{array}$ & $\begin{array}{c}\text { Yun } \\
\text { et al, } \\
2011(21)\end{array}$ & $\begin{array}{c}\text { Kawamori } \\
\text { et al, } \\
2009(25)\end{array}$ & $\begin{array}{c}\text { Nijpels } \\
\text { et al, } \\
2008(26)\end{array}$ & $\begin{array}{c}\text { Koyasu } \\
\text { et al, } \\
2010(7)\end{array}$ \\
\hline Patients, $\mathrm{n}$ & 115 & 40 & 100 & 100 & 81 & 61 & 60 & 163 & 1780 & 118 & 81 \\
\hline \multicolumn{12}{|l|}{ Age } \\
\hline Treatment & $54.8 \pm 7.4$ & $40 \pm 6.2$ & - & $53.20 \pm 5.3$ & $53 \pm 8.9$ & - & $58 \pm 17$ & $66.9 \pm 6.2$ & $55.7 \pm 9.08$ & $58.5 \pm 7.9$ & $66.1 \pm 8.6$ \\
\hline Control & $55.6 \pm 6.9$ & $39.6 \pm 6.8$ & - & $54.60 \pm 5.3$ & $52.2 \pm 8.2$ & - & $56 \pm 16$ & $66.2 \pm 4.7$ & $55.7 \pm 9.16$ & $56.5 \pm 7.0$ & $66.5 \pm 8.0$ \\
\hline \multicolumn{12}{|c|}{ Body mass index, kg/m² } \\
\hline Treatment & $29.5 \pm 4.3$ & $25.1 \pm 1.6$ & $26.34 \pm 3.39$ & $24.50 \pm 2.2$ & $25.95 \pm 3.28$ & - & $26.1 \pm 3.1$ & $25.26 \pm 2.84$ & - & $28.4 \pm 3.9$ & $24.9 \pm 2.7$ \\
\hline Control & $286 \pm 2.9$ & $25.0 \pm 0.9$ & $26.29 \pm 3.81$ & $24.4 \pm 2.1$ & $26.01 \pm 3.49$ & - & $26.3 \pm 3.3$ & $25.81 \pm 3.46$ & - & $29.5 \pm 3.8$ & $24.5 \pm 5.3$ \\
\hline \multicolumn{12}{|c|}{ Fasting plasma glucose, $\mathrm{mmol} / \mathrm{L}$} \\
\hline Treatment & $6.44 \pm 0.5$ & $5.61 \pm 0.55$ & $5.82 \pm 0.58$ & $6.4 \pm 0.42$ & $5.74 \pm 0.51$ & - & $6.3 \pm 0.6$ & $5.74 \pm 0.83$ & $5.8 \pm 0.55$ & $6.6 \pm 0.5$ & $5.96 \pm 0.58$ \\
\hline Control & $6.34 \pm 0.58$ & $5.56 \pm 0.58$ & $5.78 \pm 0.62$ & $6.38 \pm 0.41$ & $5.66 \pm 0.64$ & - & $6.2 \pm 0.5$ & $5.77 \pm 0.92$ & $5.85 \pm 0.56$ & $6.5 \pm 0.6$ & $6.03 \pm 0.98$ \\
\hline \multicolumn{12}{|c|}{ Postprandial plasma glucose, $\mathrm{mmol} / \mathrm{L}$} \\
\hline Treatment & $8.81 \pm 1.41$ & $9.12 \pm 0.92$ & $9.57 \pm 1.24$ & $9.25 \pm 1.03$ & $9.57 \pm 1.24$ & $9.1 \pm 1.13$ & $9.8 \pm 1.1$ & $8.42 \pm 0.76$ & $9.107 \pm 0.919$ & $9.6 \pm 0.7$ & $10.71 \pm 1.99$ \\
\hline Control & $8.83 \pm 1.27$ & $9.02 \pm 0.82$ & $9.53 \pm 1.34$ & $9.22 \pm 1.01$ & $9.43 \pm 1.64$ & $8.93 \pm 1.25$ & $9.6 \pm 1.2$ & $8.51 \pm 0.58$ & $9.185 \pm 0.941$ & $9.5 \pm 0.7$ & $10.38 \pm 2.78$ \\
\hline \multicolumn{12}{|c|}{ Glycosylated hemoglobin, \% } \\
\hline Treatment & $5.92 \pm 0.50$ & - & - & - & - & - & $6.6 \pm 0.3$ & $5.6 \pm 0.6$ & - & $5.9 \pm 0.5$ & $5.55 \pm 0.38$ \\
\hline Control & $5.73 \pm 0.55$ & - & - & - & - & - & $6.4 \pm 0.3$ & $5.7 \pm 0.5$ & - & $5.6 \pm 0.6$ & $5.59 \pm 0.39$ \\
\hline \multicolumn{12}{|c|}{ Total cholesterol, mmol/L } \\
\hline Treatment & $5.92 \pm 1.4$ & $5.02 \pm 1.08$ & $5.86 \pm 0.95$ & $5.79 \pm 0.48$ & $5.89 \pm 0.85$ & - & $6.1 \pm 1.2$ & $5.34 \pm 0.62$ & - & - & $4.61 \pm 0.73$ \\
\hline Control & $5.92 \pm 1.22$ & $5.19 \pm 1.13$ & $5.81 \pm 0.83$ & $5.72 \pm 0.45$ & $5.83 \pm 0.73$ & - & $5.8 \pm 1.1$ & $5.41 \pm 0.75$ & - & - & $4.44 \pm 0.63$ \\
\hline \multicolumn{12}{|l|}{ Triglycerides, $\mathrm{mmol} / \mathrm{L}$} \\
\hline Treatment & $2.40 \pm 2.44$ & $1.93 \pm 1.05$ & $1.75 \pm 0.51$ & $2.02 \pm 0.28$ & $1.78 \pm 0.64$ & - & $2.2 \pm 0.8$ & $1.96 \pm 0.52$ & - & - & $3.80 \pm 2.05$ \\
\hline Control & $2.66 \pm 2.61$ & $1.82 \pm 1.12$ & $1.73 \pm 0.54$ & $2.03 \pm 0.25$ & $1.74 \pm 0.42$ & - & $2.3 \pm 0.7$ & $2.08 \pm 0.64$ & - & - & $3.55 \pm 2.28$ \\
\hline Duration of study & 3.9 years & 12 weeks & 12 months & 48 weeks & 4 months & 15 weeks & 6 months & 2.4 years & 1 year & 3 years & 1 year \\
\hline Dose of acarbose & $100 \mathrm{mg}$ tid & $50 \mathrm{mg}$ bid & $50 \mathrm{mg}$ tid & $50 \mathrm{mg}$ tid & $50 \mathrm{mg}$ tid & $50 \mathrm{mg}$ tid & $50 \mathrm{mg}$ tid & $50 \mathrm{mg}$ tid & - & $50 \mathrm{mg}$ tid & $50 \mathrm{mg}$ tid \\
\hline Dose of voglibose & - & - & - & - & - & - & - & - & $0.2 \mathrm{mg}$ tid & - & - \\
\hline \multicolumn{12}{|l|}{ Compliance, \% } \\
\hline Treatment & 84 & 100 & 100 & 100 & 100 & 100 & 100 & 91 & 86 & 50 & 93 \\
\hline Control & 89 & 100 & 100 & 100 & 100 & 100 & 100 & 92 & 84 & 62 & 87 \\
\hline $\begin{array}{l}\text { Reporting of } \\
\text { randomization }\end{array}$ & Yes & Yes & Yes & Yes & Yes & Yes & Yes & Yes & Yes & Yes & Yes \\
\hline $\begin{array}{l}\text { Generation of } \\
\text { random sequence }\end{array}$ & $\begin{array}{r}\text { Computer } \\
\text { program }\end{array}$ & NR & NR & NR & NR & NR & NR & NR & $\begin{array}{l}\text { Stratified } \\
\text { random- } \\
\text { ization }\end{array}$ & $\begin{array}{r}\text { Computer } \\
\text { program }\end{array}$ & $\begin{array}{l}\text { Sealed- } \\
\text { envelope } \\
\text { method }\end{array}$ \\
\hline $\begin{array}{l}\text { Allocation } \\
\text { concealment }\end{array}$ & $\begin{array}{l}\text { Numbered } \\
\text { drug con- } \\
\text { tainers }\end{array}$ & NR & NR & NR & NR & NR & NR & NR & NR & $\begin{array}{l}\text { Numbered } \\
\text { drug }\end{array}$ & NR \\
\hline Blinding & $\begin{array}{l}\text { Double- } \\
\text { blind }\end{array}$ & NR & NR & NR & NR & NR & NR & NR & NR & NR & NR \\
\hline $\begin{array}{c}\text { Description of } \\
\text { withdrawals }\end{array}$ & Yes & No & No & No & Yes & No & No & Yes & Yes & Yes & Yes \\
\hline ITT analysis & Yes & NR & NR & NR & NR & NR & NR & NR & Yes & Yes & NR \\
\hline
\end{tabular}

Data presented as mean \pm SD unless otherwise stated. bid Twice daily; ITT Intent to treat; NR Not reported; tid Three times a day

TABLE 2

Changes in metabolic parameters between the two groups

\begin{tabular}{|c|c|c|c|}
\hline Parameters & Patients, n & Weighted mean difference $(95 \% \mathrm{CI})$ & $\mathbf{P}$ \\
\hline \multicolumn{4}{|l|}{ Change in: } \\
\hline Fasting plasma glucose, $\mathrm{mmol} / \mathrm{L}$ & 625 & $-0.21(-0.74$ to 0.32$)$ & 0.44 \\
\hline $2 \mathrm{~h}$ postprandial glucose, $\mathrm{mmol} / \mathrm{L}$ & 686 & $-1.70(-2.47$ to -0.94$)$ & $<0.0001$ \\
\hline Glycosylated hemoglobin, \% & 404 & $-0.24(-0.48$ to -0.01$)$ & 0.04 \\
\hline Body mass index, $\mathrm{kg} / \mathrm{m}^{2}$ & 437 & $-0.10(-0.74$ to -0.55$)$ & 0.76 \\
\hline Triglycerides, mmol/L & 585 & $-0.13(-0.28$ to 0.02$)$ & 0.09 \\
\hline Total cholesterol, mmol/L & 585 & $-0.09(-0.25$ to 0.07$)$ & 0.27 \\
\hline High-density lipoprotein, mmol/L & 437 & $0.01(-0.04$ to 0.06$)$ & 0.71 \\
\hline Systolic blood pressure, $\mathrm{mmHg}$ & 277 & $6.18(-4.34$ to 16.70$)$ & 0.25 \\
\hline Diastolic blood pressure, $\mathrm{mmHg}$ & 277 & $-0.38(-3.51$ to 4.27$)$ & 0.85 \\
\hline C-reactive protein, mg/L & 382 & $-1.63(-2.46$ to -0.81$)$ & 0.0001 \\
\hline Incidence of diabetes* & 1896 & $0.46(0.33$ to 0.65$)$ & $<0.00001$ \\
\hline
\end{tabular}


[95\% CI $-2.47 \mathrm{mmol} / \mathrm{L}$ to $-0.94 \mathrm{mmol} / \mathrm{L}] ; \mathrm{P}<0.00001)$ and decrease in HbA1c (WMD -0.24 [95\% CI -0.48 to -0.01$]$; $\mathrm{P}=0.04$ ). There were no significant differences in the changes of FBG, total cholesterol, triglycerides, HDL, BMI, systolic blood pressure and diastolic blood pressure between the two groups.

\section{DISCUSSION}

The present study is the first meta-analysis to determine whether alpha-GI treatment is associated with reduced progression of IMT, diabetes and serum CRP levels in patients with IGT. Our study suggests that alpha-GIs have beneficial effects on the progression of carotid IMT and diabetes in patients with IGT, and is associated with decreases in serum CRP levels. Acarbose treatment is also associated with decrease in $2 \mathrm{~h}$ postprandial glucose and HbA1c level. However, it has no effect on other metabolic parameters such as total cholesterol, triglycerides, BMI, systolic blood pressure and diastolic blood pressure. In subgroup analysis, higher doses of acarbose $(300 \mathrm{mg} /$ day $)$ had a similar effect as that of lower doses ( $150 \mathrm{mg} /$ day).

It is suggested that postprandial hyperglycemia is a risk factor for future cardiovascular events (3). Acarbose, an alpha-GI, delays the release of glucose from disaccharides and complex carbohydrates in the proximal small intestine resulting in lower postprandial glucose excursions after mixed meals (9). Our study found that alpha-GI treatment is associated with decrease in carotid IMT progression in patients with IGT. Because carotid IMT has been increasingly used as a surrogate marker for coronary atherosclerosis and an independent predictor of both stroke and cardiovascular disease (10), alphaGI therapy in IGT patients may be associated with a lower incidence of adverse cardiovascular events.

Treatment with alpha-GI slows the progression of carotid IMT in patients with IGT and DM $(11,12)$. Oyama et al's study has demonstrated that acarbose therapy is associated with beneficial effects on preventing the progression of carotid IMT in diabetic patients (13). In another study by Yamasaki et al, diabetic patients with voglibose treatment were found to have slower progression of carotid IMT compared with those without voglibose $(-0.030 \pm 0.153 \mathrm{~mm} /$ year versus $0.094 \pm 0.087 \mathrm{~mm} /$ year; $\mathrm{P}=0.0003$ ) (12). A meta-analysis suggested that alpha-GI treatment have preventive effects on myocardial infarction and any cardiovascular events in patients with T2DM (14). What remains uncertain is whether alpha-GI treatment has a beneficial cardioprotective effect on patients with IGT. Our metaanalysis shows that alpha-GI treatment in IGT patients is associated with an decrease in IMT.

Our meta-analysis found that alpha-GIs reduced the incidence of T2DM (OR 0.46). It is, however, important to note that only two studies were included in the analysis and the result may be strongly influenced by one large study. In addition, diabetes is a complex disease influenced by many other factors including blood pressure control and genetic susceptibility; therefore, extra precaution is needed in interpreting the result that a single drug can prevent the incidence of diabetes. However, there is no doubt that alpha-GIs do reduce the postprandial glucose level, as demonstrated by many studies. Further investigation is required to determine whether it actually reduces or delays the incidence of diabetes.

It is already known that vascular inflammation plays a critical role in the pathogenesis of atherosclerosis and mediates various stages of

\section{REFERENCES}

1. Shaw JE, Sicree RA, Zimmet PZ. Global estimates of the prevalence of diabetes for 2010 and 2030. Diabetes Res Clin Pract 2010;87:4-14.

2. Haffner SM, Lehto S, Ronnemaa T, Pyorala K, Laakso M. Mortality from coronary heart disease in subjects with type 2 diabetes and in nondiabetic subjects with and without prior myocardial infarction. N Engl J Med 1998;339:229-34.

3. Tominaga M, Eguchi H, Manaka H, Igarashi K, Kato T, Sekikawa A. Impaired glucose tolerance is a risk factor for cardiovascular disease, but not impaired fasting glucose. The Funagata Diabetes Study. Diabetes Care 1999;22:920-4. atherosclerotic plaque formation. Inflammatory biomarkers such as CRP are useful tools to assess this process. Festa et al (6) have proved that elevated CRP level was more strongly associated with postchallenge hyperglycemia than with fasting glucose. Haidari et al (15) have also shown that CRP level has a strong association with stable coronary artery disease. In the prospective Prevention of Renal and Vascular Endstage Disease (PREVEND) study of subjects without previous documented coronary artery disease, it was found that CRP levels at baseline were associated with angiographic characteristics and clinical consequences of plaque instability during follow up (16). Our study shows that alpha-GI treatment is associated with decrease in CRP levels in patients with IGT. Therefore, it can be assumed that the cardioprotective effect of acarbose therapy in IGT patients may have resulted through the modification of inflammatory markers such as CRP. Larger sample size RCTs are still needed for further investigation of the exact effect of alpha-GI on adverse cardiovascular events in patients with IGT.

Our meta-analysis found that alpha-GI therapy was associated with a decrease in $2 \mathrm{~h}$ postprandial glucose and $\mathrm{HbAlc}$ in patients with IGT. A Cochrane systematic review has shown that alpha-GI therapy had beneficial effect on FBG, PBG, HbA1c and BMI (17). Hanefeld et al (14) has also revealed that acarbose therapy was associated with reduction in FBG, PBG, HbA1c, triglycerides, BMI and diastolic blood pressure in patients with T2DM (14). In contrast to those studies, our meta-analysis did not find statistically significant differences in fasting glucose level. It may be due to the fact that some of the studies might not be long enough to detect the changes in fasting glucose level. However, our meta-analysis did find a decrease in $\mathrm{HbAlc}$ level, which indicates better glycemic control. Our study did not find any statistically significant difference in other metabolic parameters related to atherosclerosis.

The present meta-analysis has several limitations. First, there were several factors that might contribute to the clinical heterogeneity of the study such as different dosages of alpha-GIs and different follow-up period. Second, most patients enrolled in the study were Asians (apart from approximately 233 European patients). Therefore, generalization of the findings to more diverse patient population should be made with caution. Third, some clinical outcomes and metabolic parameters were unavailable in some studies, which would affect the integrity of the meta-analysis. Finally, there were some differences in the method of carotid IMT measurement across the included studies that could add clinical heterogeneity to the study.

\section{CONCLUSION}

The present meta-analysis suggests that alpha-GI therapy has the potential to prevent the progression of diabetes and carotid IMT in IGT, thereby reducing cardiovascular events. However, large, multicentre randomized studies are still warranted to further clarify the cardioprotective effect of alpha-GI and whether reducing the carotid IMT with alpha-GI affects cardiovascular-related morbidity and mortality of IGT patients.

DISCLOSURES: The authors have no conflicts of interest to declare.

SOURCES OF FUNDING: This research received no specific grant from any funding agency in the public, commercial, or not-for-profit sectors.

4. de Vegt F, Dekker JM, Ruhe HG, et al. Hyperglycaemia is associated with all-cause and cardiovascular mortality in the Hoorn population: The Hoorn Study. Diabetologia 1999;42:926-31.

5. O'Leary DH, Polak JF, Kronmal RA, Manolio TA, Burke GL, Wolfson SK Jr. Carotid-artery intima and media thickness as a risk factor for myocardial infarction and stroke in older adults. Cardiovascular Health Study Collaborative Research Group. N Engl J Med 1999;340:14-22.

6. Festa A, D'Agostino R Jr, Tracy RP, Haffner SM. C-reactive protein is more strongly related to post-glucose load glucose than to fasting 
glucose in nondiabetic subjects: The Insulin Resistance Atherosclerosis Study. Diabet Med 2002;19:939-43.

7. Koyasu M, Ishii H, Watarai M, et al. Impact of acarbose on carotid intima-media thickness in patients with newly diagnosed impaired glucose tolerance or mild type 2 diabetes mellitus: A one-year, prospective, randomized, open-label, parallel-group study in Japanese adults with established coronary artery disease. Clin Ther 2010;32:1610-7.

8. Hodis HN, Mack WJ, LaBree L, et al. The role of carotid arterial intima-media thickness in predicting clinical coronary events. Ann Intern Med 1998;128:262-9.

9. Bischoff $H$. The mechanism of alpha-glucosidase inhibition in the management of diabetes. Clin Invest Med 1995;18:303-11.

10. Chambless LE, Folsom AR, Clegg LX, et al. Carotid wall thickness is predictive of incident clinical stroke: The Atherosclerosis Risk in Communities (ARIC) study. Am J Epidemiol 2000;151:478-87.

11. Hanefeld M, Chiasson JL, Koehler C, Henkel E, Schaper F, Temelkova-Kurktschiev T. Acarbose slows progression of intimamedia thickness of the carotid arteries in subjects with impaired glucose tolerance. Stroke 2004;35:1073-8.

12. Yamasaki Y, Katakami N, Hayaishi-Okano R, et al. Alphaglucosidase inhibitor reduces the progression of carotid intimamedia thickness. Diabetes Res Clin Pract 2005;67:204-10.

13. Oyama T, Saiki A, Endoh K, et al. Effect of acarbose, an alphaglucosidase inhibitor, on serum lipoprotein lipase mass levels and common carotid artery intima-media thickness in type 2 diabetes mellitus treated by sulfonylurea. J Atheroscler Thromb 2008;15:154-9.

14. Hanefeld M, Cagatay M, Petrowitsch T, Neuser D, Petzinna D, Rupp M. Acarbose reduces the risk for myocardial infarction in type 2 diabetic patients: Meta-analysis of seven long-term studies. Eur Heart J 2004;25:10-6.

15. Haidari M, Javadi E, Sadeghi B, Hajilooi M, Ghanbili J. Evaluation of C-reactive protein, a sensitive marker of inflammation, as a risk factor for stable coronary artery disease. Clin Biochem 2001;34:309-15.

16. Geluk CA, Post WJ, Hillege HL, et al. C-reactive protein and angiographic characteristics of stable and unstable coronary artery disease: Data from the prospective PREVEND cohort. Atherosclerosis 2008;196:372-82.

17. Van de Laar FA, Lucassen PL, Akkermans RP, Van de Lisdonk EH, De Grauw WJ. Alpha-glucosidase inhibitors for people with impaired glucose tolerance or impaired fasting blood glucose. Cochrane Database Syst Rev 2006:CD005061.

18. Yu Li-na, Gu Shui-ming, Miao Pei-zhi, et al. The effects of acarbose on serum endothelin, C-reactive protein and fibrinogen in impaired glucose tolerance patients. IMHGN 2011;17:33-36.

19. Su R-T, Han X-J. Effect of acarbose intervention on cases with impaired glucose tolerance. Chin J Postgrad Med 2006;29:14-6.

20. Tang Z-H, Yang H. The efects of Glucobay on endothelin, nitric oxide and C-reactive protein in impaired glucose tolerance patients. Internal Med China 2008;3:176-77.

21. Yun P, Xiao H, Chen X, et al. Effect of acarbose on elderly patients with coronary heart disease complicating impaired glucose tolerance and protective mechanism. Clinical Focus 2011;26:1680-83.

22. Wu X, Yu W-G. The effect of acarbose on carotid atherosclerosis in patients with impaired glucose tolerance. J Chinese Community Doctors 2011;13:43.

23. Liu H, Sun H-Y, Fan J. Clinical observation of acarbose early intervention for IGT patients. Chinese J Misdiagn 2008;8:7341-42.

24. Huang P, Xie Z. The effect of acarbose on C-reactive protein in patients with impaired glucose tolerance. J Youjiang Medical College Nationalities 2008;30:762-3.

25. Kawamori R, Tajima N, Iwamoto Y, et al. Voglibose for prevention of type 2 diabetes mellitus: A randomised, double-blind trial in Japanese individuals with impaired glucose tolerance. Lancet 2009;373:1607-14.

26. Nijpels G, Boorsma W, Dekker JM, et al. Study of the effects of acarbose on glucose metabolism in patients predisposed to developing diabetes: The Dutch Acarbose Intervention Study in persons with Impaired glucose tolerance (DAISI). Diabetes Metab Res Rev 2008;24:611-6. 